\title{
Self Ear Cleaning: Prevalence and Profile among School Children in Ekiti, Nigeria
}

\author{
Toye Gabriel Olajide ${ }^{1}$, Oyebanji Anthony Olajuyin ${ }^{2}$, Adebisi Paul Eletta ${ }^{3}$, \\ Segun Mathew Agboola ${ }^{4}$, Adesola Olusegun Busari ${ }^{5}$, Idowu Adebara ${ }^{6}$
}

\begin{abstract}
${ }^{1}$ Department of Ear, Nose and Throat, Federal Teaching Hospital, Ido Ekiti/Afe Babalola University, Ado Ekiti (ABUAD), Ado Ekiti, Nigeria

${ }^{2}$ Department of Ear, Nose and Throat, Ekiti State University Teaching Hospital, Ado Ekiti, Nigeria

${ }^{3}$ Department of Ear, Nose and Throat, Federal Medical Centre, Bida, Nigeria

${ }^{4}$ Department of Family Medicine, Federal Teaching Hospital, Ido Ekiti/Afe Babalola University, Ado Ekiti (ABUAD), Ado Ekiti, Nigeria ${ }^{5}$ Department of Internal Medicine, Federal Teaching Hospital, Ido Ekiti/Afe Babalola University, Ado Ekiti (ABUAD), Ado Ekiti, Nigeria ${ }^{6}$ Department of Obstetric \& Gynaecology, Federal Teaching Hospital, Ido Ekiti/Afe Babalola University, Ado Ekiti (ABUAD), Ado Ekiti, Nigeria

Email: olajidetg@abuad.edu.ng, oyebanjiolajuyin@yahoo.com, elettaadebisi@yahoo.com,slmagboola@yahoo.com, olubusari@yahoo.com, idowu.adebara@gmail.com, *toyeolajide@yahoo.co.uk
\end{abstract}

How to cite this paper: Olajide, T.G., Olajuyin, O.A., Eletta, A.P., Agboola, S.M., Busari, A.O. and Adebara, I. (2019) Self Ear Cleaning: Prevalence and Profile among School Children in Ekiti, Nigeria. Journal of Biosciences and Medicines, 7, 25-32. https://doi.org/10.4236/jbm.2019.74003

Received: March 6, 2019

Accepted: April 8, 2019

Published: April 11, 2019

Copyright ( 2019 by author(s) and Scientific Research Publishing Inc. This work is licensed under the Creative Commons Attribution International License (CC BY 4.0).

http://creativecommons.org/licenses/by/4.0/

(c) (i) Open Access

\begin{abstract}
Background: Self-cleaning of ears with different objects is a common practice among school children with scanty report in literature. Aim: The aim of this study was to determine the prevalence and profile of self-ear cleaning among school children. Methods: It was a cross-sectional institutional-based study which was carried out among school children in Ekiti, south western Nigeria from January 2017, to March 2017. Results: A total of 174 students participated in this study. Their age ranged between 13 and 17 years. The highest number of participant was found at the age of 15 years. One hundred and eighteen $(67.8 \%)$ of them had carried out self ear cleaning. Personal hygiene was the commonest reason for self ear cleaning in $28.8 \%$ of the students. Cotton buds were mostly used by the respondents in $51.7 \%$ of them. Injury to the external auditory canal (EAC) was the most recorded complications. Conclusion: The outcome of this study shows that self-ear cleaning practices were common among school children with a prevalence of $67.8 \%$. Cotton buds were the commonest objects used. Avoidable complications were reported among respondents. There is a need to intensify efforts on public enlightenment programme and the establishment of school health programme in our various schools.
\end{abstract}

\section{Keywords}

Self Ear Cleaning, Prevalence, Profile, School Children 


\section{Introduction}

Self-ear cleaning is described as the insertion of objects into the ear canal to clean it. This habit is a common practice worldwide and has the potential to compromise the integrity of the ear as a natural, self-cleaning mechanism [1] [2] [3] [4] [5]. Major reasons for self-ear cleaning were to remove ear wax inform of personal hygiene and because earwax was considered as a dirt or cosmetic nuisance from the ear [1] [4] [6] [7] [8] [9] [10]. Other reasons for self ear cleaning include the feeling of ear discomfort, earache, hearing impairment, ear blockage, and itching [11] [12] [13]. However, other people see this habit as part of personal hygiene so it is mandatory and normal [14]. Insertions of different objects into the ear are common not only in adults but also in pediatric population either by children themselves or by their parents. The habit was said to be unnecessary and potentially dangerous to the user [14]. The external auditory canal (EAC) has the ability to clean itself, which is made possible by the cleansing function of cerumen, a naturally occurring substance that cleans, protects and lubricates the external auditory canal [1]. It constantly migrates towards the outer part of the external auditory canal, this being assisted by jaw movement [15]. Foreign materials adhere to the cerumen, thus preventing it from plugging the ear or reaching the tympanic membrane [16]. Hence, a process that makes cleaning the ear canal unnecessary [17]. The combination of secretions from the ceruminous and sebaceous glands and desquamated epithelium from the tympanic membrane and skin lining the external auditory canal forms the ear wax [1] [18] [19]. Cerumen exerts a protective effect by maintaining an acidic milieu ( $\mathrm{pH}$ of $5.2-7.0$ ) in the external auditory canal whilst also lubricating the canal [20] [21]. It has also been shown to have significant antibacterial and antifungal properties 21. It was reported that the most preferred object [2] [3] [14] for self-ear cleaning is cotton buds, nevertheless, some use feathers, biro pen cover, broomstick, matchsticks and finger, [2] [3] [22]. This practice impairs the natural cleansing mechanism of the ear. Self-ear cleaning has widely been condemned by otolaryngologists due to well documented complications which include trauma, impacted ear wax, infection and retention of the cotton bud [1] [2] [3] [14] [22] [23] [24]. This study was carried out to determine the prevalence and profile of self-ear cleaning among school children. Such study had not been conducted among students in our locality.

\section{Methodology}

This was a cross sectional descriptive study conducted among students of two secondary schools in Ekiti, south western, Nigeria from January 2017 to March 2017. All consented male and female students from Junior Secondary 3 (JS3) and Senior Secondary 3 (SS3) of the school were included in the study. Permission was sought from school authority prior to conduct of this study. All the participants were assured of confidentiality. They were also not to write any information that may enable them to be identified. Information was obtained through 
administered pre-tested semi-structured questionnaires. The questionnaire contained information on age, sex, the practice of ear cleaning, type of object used, reasons for self-ear cleaning and associated complications. All the participants had detailed Ear, Nose and Throat examination done. Exclusion criteria include all the students that did not gave consent and those with ear canal injury and tympanic membrane perforation that were not due to self-ear cleaning. Data collected was analyzed using IBM SPSS version 23.0. The data were expressed in simple frequency tables and charts. Ethical clearance was obtained from ethical committee of our institution.

\section{Results}

A total of 174 students were studied. Their age ranged between 13 and 17 years with a mean of $15.02 \pm 1.33 \mathrm{SD}$. The highest number of participant was found at age 15 years (Figure 1$)$. There were 80 (46.0\%) males and $94(54.0 \%)$ females given a male to female ratio of 1:1.2. Majority (75.3\%) were Christian. One hundred and eighteen (67.8\%) of them had carried out self ear cleaning. Table 1 . Of those that did self ear cleaning, personal hygiene was the commonest reason in $34(28.8 \%)$ followed by ear itching in $25(21.2 \%)$. Other reasons are shown in Table 2. The commonest object used for ear cleaning was cotton buds in $51.7 \%$ of our respondents. Other objects are shown in Figure 2. The commonest diagnosis seen among the participants that clean their ear was Allergy in 46 (39.0\%), followed by ear wax impaction in 32 (27.1\%), Foreign body in $16(13.6 \%)$. Others are shown in Table 3. Complications recorded among those that clean their ear are injuries to EAC in $30.5 \%$, FB impaction in $12.7 \%$, Traumatic TM perforation. However, $50.0 \%$ of the participants did not have any complication Table 4. Treatment given were conservative/medical in 63 (36.2\%), aural toilet/wick dressing in 20 (11.5\%), foreign body and wax removal by instrumentation in 19 (10.9\%) while ear syringing was done in 8 (4.6\%) students. Majority of our patients did well on systemic antibiotics, topical ear drops, systemic decongestant and anti-allergic drugs. We are able to achieve dry ear for those students on aural toilet and wick dressings.

\section{Discussion}

The practice of self-ear cleaning has been reported worldwide [1] and has also been condemned worldwide. It was not limited only to an adult population as school children also engaged in the practice. In our study the prevalence of self-ear cleaning was $67.8 \%$. Though this was lower than that reported by Adegbiji et al. (91.1\%) in the study they carried out among peadiatric age group [25]. Their study was hospital based. The mean age in our study was 15.0 years; while the mean age of commencement of self ear cleaning was reported to be 7.6 years by Olaosun et al. [4], reinforcing the importance of conditioning during childhood as an important factor in the development of the habit. The commonest reason for self ear cleaning in this study was for personal hygiene. Same reason 
Table 1. Socio demographic characteristics and practice of self ear cleaning $(n=174)$.

\begin{tabular}{ccc}
\hline Variable & Frequency (n) & Percentage (\%) \\
\hline Sex & 80 & 46.0 \\
Male & 94 & 54.0 \\
Female & & \\
\hline Religion & 131 & 75.3 \\
\hline Christianity & 43 & 24.7 \\
Islamic & & 86.2 \\
\hline Ethnicity & 150 & 13.8 \\
\hline Yoruba & 24 & \\
Ibo & & 67.8 \\
\hline Self ear cleaning & 118 & 32.2 \\
\hline Yes & 56 & \\
No & &
\end{tabular}

Table 2. Reasons for self-ear cleaning.

\begin{tabular}{ccc}
\hline Reasons & Frequency $(\mathrm{n})$ & Percentage (\%) \\
\hline Personal hygiene & 34 & 28.8 \\
Itching & 25 & 21.2 \\
Dirt/wax & 22 & 18.6 \\
Ear blockage & 15 & 12.7 \\
Irritation & 8 & 6.8 \\
Ear ache & 8 & 6.8 \\
Ear discharge & 6 & 5.1 \\
Total & 118 & 100.0 \\
\hline
\end{tabular}

Table 3. Diagnosis among students.

\begin{tabular}{ccc}
\hline Diagnosis & Frequency $(\mathrm{n})$ & Percentage (\%) \\
\hline Allergy & 46 & 39.0 \\
Ear wax impaction & 32 & 27.1 \\
Foreign body & 16 & 13.6 \\
Otitis media & 13 & 11.0 \\
Otitis external & 7 & 5.9 \\
Hearing loss & 4 & 3.4 \\
Total & 118 & 100.0 \\
\hline
\end{tabular}

was reported by other authors [1] [13] [25]. However Ear Itching was the commonest reason reported by Olajide et al. 14 while in other studies wax removal was the commonest reason [2] [4] [5]. It is a common knowledge that attempting 
Table 4. Complications following self-ear cleaning.

\begin{tabular}{ccc}
\hline Complications & Frequency $(\mathrm{n})$ & Percentage $(\%)$ \\
\hline No complication & 59 & 50.0 \\
EAC injury & 36 & 30.5 \\
Foreign body impaction & 15 & 12.7 \\
Traumatic TM perforation & 8 & 6.8 \\
Total & & \\
\hline
\end{tabular}

NB: EAC (external auditory canal), TM (tympanic membrane).

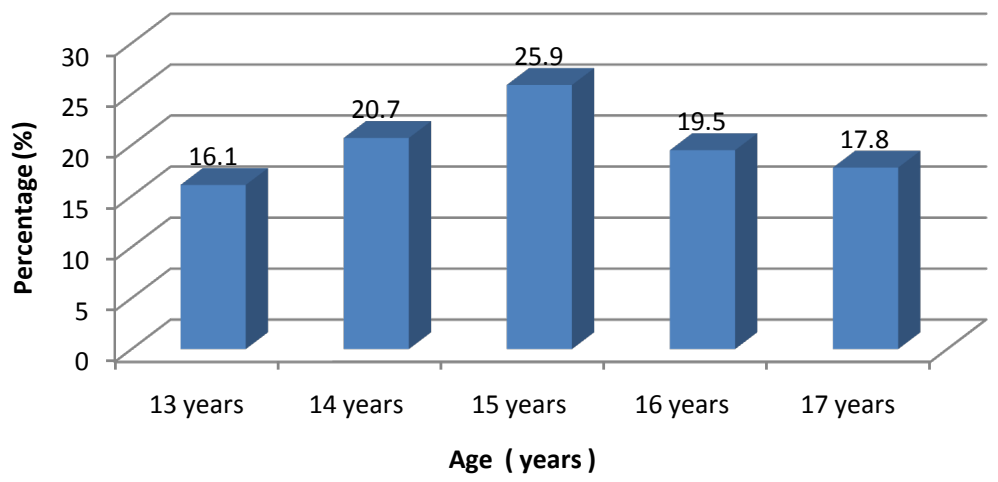

Figure 1. Showing age distribution of students.

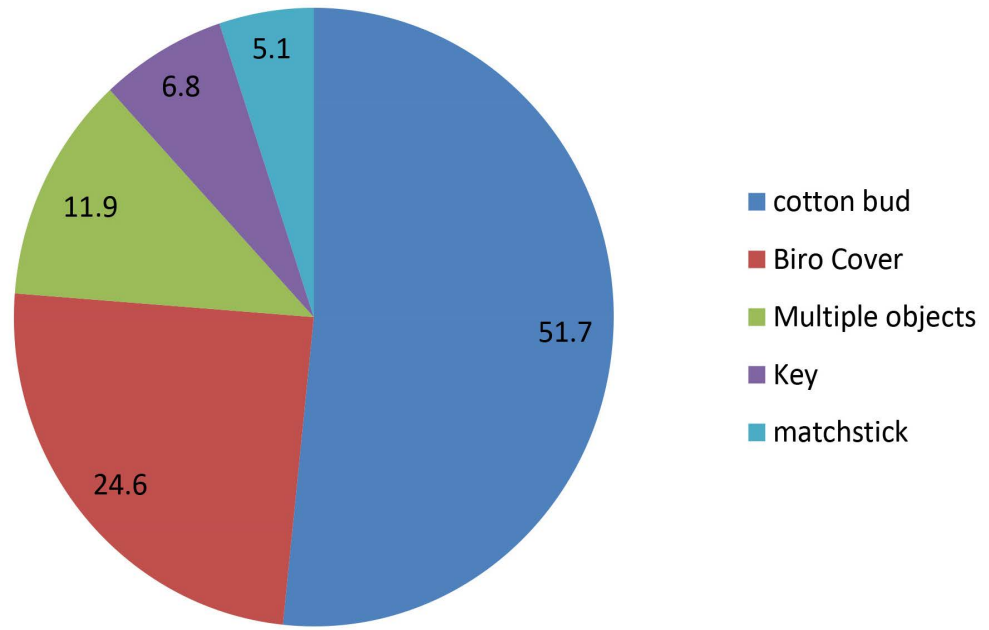

Figure 2. Objects used for self cleanining.

to clean wax out of the ear with swabs is one habit that everyone feels good to do. Also some people feel incomplete if they don't do it particularly after a bath [26]. More than half of our respondents use cotton buds as their commonest object for cleaning their ears which was similar to some report by other authors [4] [27] [28]. The practice of using cotton bud and possibly other objects to scratch ear canal is dangerous, as they may easily cause trauma and subsequently infection may follow. Most diagnosis encountered were Allergy, ear wax impaction, foreign body, otitis media, otitis externa and hearing loss. Allergy and otitis ex- 
tern a inform of otomycosis might cause itching in the ear leading to self ear cleaning. Aggressive cleaning of ear especially with cotton buds may lead to pushing of wax deeply into the canal causing ear wax impaction and eventually blockage and hearing impairment. Most of the foreign bodies observed were cotton buds which might probably got retained in the EAC during self cleaning. Complications observed by respondents were bruises of EAC, foreign bodies' impaction. Tympanic membrane perforation was noticed during the study. Injury to the EAC usually associated with pain and subsequently infections may follow if not properly treated. Injury rate between $2 \%-5 \%$ including bruising and bleeding in the EAC was reported in other studies [1] [29]. Most of the complications were treated conservatively and medically with antibiotics (both systemic and topical ear drop), systemic decongestant, aural toilet and wick dressings. Ear wax was removed by ear syringing while foreign body was removed by instrumentation under direct vision. Other treatment option of removing ear wax include the use a cerumenolytic, topical therapy, irrigation, suctioning, syringing and other manual removal techniques [30]. The limitations of this study include sampling bias. The fact that it was conducted in two schools; it may not be true representative of general population of students.

\section{Conclusion}

The outcome of this study shows that self-ear cleaning practices were common among school children with a prevalence of $67.8 \%$. Cotton buds were the commonest objects used. Avoidable complications were reported among respondents. There is a need for primary health care physicians and ear specialist to intensify efforts in the area of health education and public enlightenment programs. Establishment of school health programme in our various schools is also advocated.

\section{Acknowledgements}

The authors are most grateful to the management and staff of African Comprehensive High School and Eleyo High School Ikere Ekiti and all the students who participated in this study.

\section{Conflicts of Interest}

No Conflicts of interest was declared by the Authors (DRS Olajide TG, Olajuyin AO, and Eletta AP, Agboola SM, Busari OA, Adebara I).

\section{References}

[1] Afolabi, A.O., Kodiya, A.M., Bakari, A. and Ahmad, B.M. (2009) Attitude of Self Ear Cleaning in Black Africans: Any Benefit? East African Journal of Public Health, 6 , 43-46.

[2] Lee, L.M., Govindaraju, R. and Hon, S.K. (2005) Cotton Bud and Ear Cleaning: A Loose Tip Cotton Bud? Medical Journal of Malaysia, 60, 85-88. 
[3] Hobson, J.C. and Lavy, J.A. (2005) Use and Abuse of Cotton Buds. Journal of the Royal Society of Medicine, 98, 360-361. https://doi.org/10.1177/014107680509800808

[4] Olaosun, O.A. (2014) Self-Ear-Cleaning among Educated Young Adults in Nigeria. Journal of Family Medicine and Primary Care, 3, 17-21. https://doi.org/10.4103/2249-4863.130262

[5] Amutta, S.B., Mufutau, A.Y., Kufre, R.I., et al. (2013) Sociodemographic Factors and Prevalence of Self-Ear Cleaning in Sokoto Metropolis. International Journal of Otorhinolaryngology and Head \& Neck Surgery, 2, 276-279.

[6] Roland, P.S., Smith, T.L., Schwartz, S.R., Rosenfeld, R.M., Ballachanda, B., Earll, J.M., et al. (2008) Clinical Practice Guideline: Cerumen Impaction. American Academy of Otolaryngology and Head \& Neck Surgery, 139, S1-S21. https://doi.org/10.1016/j.otohns.2008.06.026

[7] Guest, J.F., Greener, M.J., Robinson, A.C. and Smith, A.F. (2004) Impacted Cerumen: Composition, Production, Epidemiology and Management. Quarterly Journal of Medicine, 97, 477-488. https://doi.org/10.1093/qjmed/hch082

[8] Propst, E.J., George, T., Janjua, A., James, A., Campisi, P. and Forte, V. (2012) Removal of Impacted Cerumen in Children Using an Aural Irrigation System. International Journal of Pediatric Otorhinolaryngology, 76, 1840-1843.

https://doi.org/10.1016/j.ijporl.2012.09.014

[9] Gadanya, M., Abubakar, S., Ahmed, A. and Maje, A.Z. (2016) Prevalence and Attitude of Self-Ear Cleaning with Cotton Buds among Doctors at Aminu Kano Teaching Hospital, Northwestern Nigeria. Nigerian Journal of Surgical Research, 17, 43-47. https://doi.org/10.4103/1595-1103.194215

[10] Sharp, J.F., Wilson, J.A., Ross, L. and Barr-Hamilton, R.M. (1990) Ear Wax Removal: A Survey of Current Practice. BMJ, 301, 1251-1253. https://doi.org/10.1136/bmj.301.6763.1251

[11] Jegoux, F., Legent, F. and de Montreuil, C.B. (2002) Chronic Cough and Ear Wax. Lancet, 360, 618. https://doi.org/10.1016/S0140-6736(02)09786-6

[12] Junk, T.T.K. and Jinn, T.H. (2003) Diseases of the External Ear. In: James, B., Ed., Ballenger's Otorhinolaryngology, Head and Neck Surgery, 16th Edition, BC Decker Inc., Hamilton, Canada, 230-234.

[13] Adegbiji, W.A., Olajide, T.G. and Nwawolo, C.C. (2018) Patterns of Self Ear Cleaning among Otorhinolaryngology Patients in Developing Country. Asian Journal of Science and Technology, 9, 7892-7896.

[14] Olajide, T.G., Usman, A.M. and Eletta, A.P. (2015) Knowledge, Attitude and Awareness of Hazards Associated with Use of Cotton Bud in a Nigerian Community. International Journal of Otolaryngology and Head \& Neck Surgery, 4, 248-253. https://doi.org/10.4236/ijohns.2015.43042

[15] Roland, P.S., Marple, B.F. and Mayerhoff, W.L. (1997) Hearing Loss. 2nd Edition, Thieme Medical Publishers Inc., New York.

[16] Oron, Y., Lazar-Zwecker, I., Levy, D., Kreitler, S. and Roth, Y. (2009) Cerumen Removal: Comparison of Cerumenolytic Agents and Effect on Cognition among the Elderly. Archives of Gerontology and Geriatrics, 52, 228-232. https://doi.org/10.1016/j.archger.2010.03.025

[17] Beatrice, F., Bucolo, S. and Cavallo, R. (2009) Earwax, Clinical Practice. ACTA Otorhinolaryngologica Italica, 29, 1-20.

[18] Adegbiji, W.A., Alabi, B.S., Olajuyin, O.A. and Nwawolo, C.C. (2014) Earwax Im- 
paction: Symptoms, Predisposing Factors and Perception among Nigerians. Journal of Family Medicine and Primary Care, 3, 371-382.

[19] Burton, M.J. and Doree, C. (2009) Ear Drops for the Removal of Ear Wax. Cochrane Database of Systematic Reviews, Article No. CD004326. https://doi.org/10.1002/14651858.CD004326.pub2

[20] Carr, M.M. and Smith, R.L. (2001) Ceruminolytic Efficacy in Adults versus Children. Journal of Otolaryngology, 30, 154-156. https://doi.org/10.2310/7070.2001.20001

[21] Lum, C.L., Jeyanthi, S., Prepageran, N., Vadivelu, J. and Raman, R. (2009) Antibacterial and Antifungal Properties of Human Cerumen. The Journal of Laryngology and Otology, 123, 375-378. https://doi.org/10.1017/S0022215108003307

[22] Oladeji, S.M., Babatunde, O.T., Adenekan, A.K., Nwawolo, C.C., Uche-Okonkwo, K.C. and Johnson, K.J. (2015) Self Ear Cleaning among Health Workers in Nigeria. IOSR Journal of Dental and Medical Sciences, 14, 122-126.

[23] Salahuddin, A., Syed, A., Syed, M., Sibghatullah, R., Tauhidul, I. and Bashir, A (2014) Association of Dermatological Conditions of External Ear with the Use of Cotton Buds. Journal of Enam Medical College, 4, 174-176.

https://doi.org/10.3329/jemc.v4i3.20956

[24] Raman, R. (1977) Should Cotton Buds Be Banned? Tropical Doctor, 27, 250.

[25] Adegbiji, A.W., Olajide, T.G. and Nwawolo, C.C. (2018) Paediatric Presentation of Ear Cleaning in a West African Country. Port Harcourt Medical Journal, 12, 136-141. https://doi.org/10.4103/phmj.phmj_6_18

[26] Obinna, C. (2019) The Ear, the Cotton Bud and the Seven Signs of Trouble. Medical World Nigeria.

https://www.medicalworldnigeria.com/read.php?year=2017\&month=01\&slug=theear-the-cotton-bud-and-the-seven-signs-of-trouble-by-chioma-obinna\#.XGEphToo IV

[27] Ogar, S.A., Odekunle, R.R., Enesil, I.E. and Lawal, W.D. (2018) Attitude and Awareness of Health Hazards Associated with Self-Ear Cleaning Using Cotton Buds amongst Adult Patients Attending Federal Medical Centre Lokoja, North Central Nigeria. The Nigerian Health Journal, 18, 8-13.

[28] Khan, N.B., Thaver, S. and Govender, S.M. (2017) Self-Ear Practices and the Associated Risk of Ear Injuries and Ear-Related Symptoms in a Group of University Students. Journal of Public Health in Africa, 8, 149-154.

https://doi.org/10.4081/jphia.2017.555

[29] Ullauri, A., Smith, A., Espinel, C., Jimenez, C., Salazar, C. and Castrillon, R. (2014) WHO Ear and Hearing Disorders: Ecuador National Study 2008-2009. Conference Papers in Science, 2014, Article ID: 847526. https://doi.org/10.1155/2014/847526

[30] Roland, P.S., Smith, T.L., Schwartz, S.R., et al. (2008) Clinical Practice Guideline: Cerumen Impaction. Otolaryngology_Head and Neck Surgery, 139, S1-S21. https://doi.org/10.1016/j.otohns.2008.06.026 